॥ This article has been updated from its originally published version to correct the Results section of the abstact and text and Table 2.

See the corresponding erratum notice in this issue, p 678. «

\title{
Predictors of recurrence and high growth rate of residual meningiomas after subtotal resection
}

\author{
*Joshua Materi, BS, ${ }^{1}$ David Mampre, BS, ${ }^{1}$ Jeff Ehresman, BS, ${ }^{1}$ Jordina Rincon-Torroella, MD, ${ }^{1}$ and \\ Kaisorn L. Chaichana, MD² \\ 'Department of Neurosurgery, Johns Hopkins University, Baltimore, Maryland; and 'Department of Neurosurgery, Mayo Clinic,
Jacksonville, Florida
}

\begin{abstract}
OBJECTIVE The extent of resection has been shown to improve outcomes in patients with meningiomas. However, resection can be complicated by constraining local anatomy, leading to subtotal resections. An understanding of the natural history of residual tumors is necessary to better guide postsurgical management and minimize recurrence. This study seeks to identify predictors of recurrence and high growth rate following subtotal resection of intracranial meningiomas.

METHODS Adult patients who underwent primary surgical resection of a WHO grade I meningioma at a tertiary care institution from 2007-2017 were retrospectively reviewed. Volumetric tumor measurements were made on patients with subtotal resections. Stepwise multivariate proportional hazards regression analyses were performed to identify factors associated with time to recurrence, as well as stepwise multivariate regression analyses to assess for factors associated with high postoperative growth rate.

RESULTS Of the 141 patients (18\%) who underwent radiographic subtotal resection of an intracranial meningioma during the reviewed period, $74(52 \%)$ suffered a recurrence, in which the median (interquartile range, IQR) time to recurrence was 14 (IQR 6-34) months. Among those tumors subtotally resected, the median pre- and postoperative tumor volumes were $17.19 \mathrm{~cm}^{3}\left(\mathrm{IQR} 7.47-38.43 \mathrm{~cm}^{3}\right)$ and $2.31 \mathrm{~cm}^{3}\left(\mathrm{IQR} 0.98-5.16 \mathrm{~cm}^{3}\right)$, which corresponded to a percentage resection of $82 \%$ (IQR $68 \%-93 \%$ ). Postoperatively, the median growth rate was $0.09 \mathrm{~cm}^{3} /$ year (IQR 0-1.39 $\mathrm{cm}^{3} /$ year). Factors associated with recurrence in multivariate analysis included preoperative tumor volume (hazard ratio [HR] 1.008, 95\% confidence interval [Cl] 1.002-1.013, $p=0.008$ ), falcine location (HR 2.215, 95\% Cl 1.179-4.161, $p=0.021)$, tentorial location (HR 2.410,95\% Cl 1.203-4.829, $p=0.024)$, and African American race (HR 1.811, 95\% Cl 1.042-3.146, $p$ $=0.044)$. Residual volume (RV) was associated with high absolute annual growth rate (odds ratio [OR] 1.175, 95\% Cl 1.078-1.280, $p<0.0001)$, with the maximum RV benefit at $<5 \mathrm{~cm}^{3}(\mathrm{OR} 4.056,95 \% \mathrm{Cl} 1.675-9.822, \mathrm{p}=0.002)$.
\end{abstract}

CONCLUSIONS By identifying predictors of recurrence and growth rate, this study helps identify potential patients with a high chance of recurrence following subtotal resection, which are those with large preoperative tumor volume, falcine location, tentorial location, and African American race. Higher RVs were associated with tumors with higher postoperative growth rates. Recurrences typically occurred 14 months after surgery.

https://thejns.org/doi/abs/10.3171/2019.10.JNS192466

KEYWORDS meningioma; radiation; recurrence; growth rate; Simpson grade; stereotactic; oncology

$\mathrm{M}$ ENINGIOMAS are mostly benign mesenchymal neoplasms representing the most common primary intracranial tumor, with an incidence of 7.86 per 100,000 people. ${ }^{4,15,26}$ Maximal resection is the standard therapeutic treatment for meningiomas..$^{19}$ Despite advances in imaging and surgical instrumentation tech- niques, subtotal resections still occur due to tumor location, size, and concern for compromising adjacent anatomy. Furthermore, the development of adjuvant therapies, namely radiation therapy, has allowed for less aggressive surgical approaches in an attempt to preserve postoperative morbidity and mortality. $24,38,43$

ABBREVIATIONS $\mathrm{CI}=$ confidence interval; $\mathrm{HR}=$ hazard ratio; IQR = interquartile range; KPS = Karnofsky Performance Scale; OR = odds ratio; RV = residual volume. SUBMITTED September 7, 2019. ACCEPTED October 28, 2019.

INCLUDE WHEN CITING Published online January 3, 2020; DOI: 10.3171/2019.10.JNS192466.

* J.M. and D.M. share first authorship of this work. 
Although meningioma growth rates vary widely as a whole, few studies have evaluated growth rate following subtotal resection. ${ }^{34}$ This study seeks to identify predictors of recurrence and growth rate following subtotal resection to better guide the clinical decision-making process, helping to individualize extent of resection and surveillance imaging protocols, as well as implementation and timing of adjuvant therapies.

\section{Methods \\ Patient Selection}

IRB approval was obtained from Johns Hopkins University prior to the start of this study. All adult patients who underwent primary resection of a WHO grade I meningioma at a tertiary care institution between March 5, 2007, and September 11, 2017, were recorded and reviewed. Patients with neurofibromatosis type 2 , presumed radiation-induced meningiomas, recurrent meningiomas, spinal meningiomas, and WHO grade II or III meningiomas were excluded. Of the 796 patients who underwent primary resection of a WHO grade I meningioma during the reviewed period, 181 patients $(22.7 \%)$ underwent radiographic subtotal resection. Nineteen patients were excluded for having less than 3 months of follow-up, 9 patients were excluded for imaging that was inadequate for volumetric measurement, and 12 patients were excluded for receiving postoperative radiation. Patients typically underwent MRI 48 hours after surgery followed by a 3 -month follow-up scan; excluding patients with less than 3 months follow-up allowed for an additional time point to track initial growth rates. The remaining 141 patients $(77.9 \%)$ were included in the analyses.

\section{Recorded Variables}

Tumor pathology and grade were determined by a senior neuropathologist in all cases according to the 2007 WHO grading system. ${ }^{26}$ The clinical, operative, and hospital records of the included patients were retrospectively reviewed. Resections were defined as subtotal when definitive residual tumor remained (Simpson grade 4 resections) on postoperative radiographic assessment able to undergo volumetric analysis. This did not include dural tails. Simpson grade 5 resections were not performed in this cohort and were therefore not included. All patients underwent a brain MRI scan with and without contrast within 48 hours of their first surgery. Recurrence was defined as definitive growth of residual tumor as assessed by a neuroradiologist. The typical imaging protocol after surgery was MRI 3 months after surgery, followed by 3 - to 6-month intervals.

\section{Volumetric Measurements}

All MR images were obtained and reviewed. Tumor volumes were determined by manually calculating tumor areas in each MRI slice, and then compiling the volumes in the z-dimension using a semiautomated PACS measurement tool (version 12.1, Carestream Health), as previously described. ${ }^{11}$ This was completed using T1-weighted MRI with gadolinium contrast, in which dural tails were not included into the volumetric measurements. When pa- tients had multiple meningiomas, only the operated tumor was assessed.

\section{Statistical Analysis}

Stepwise multivariate proportional hazards regression analyses were performed to identify potential associations between demographic, radiological, preoperative, postoperative, and pathologic variables and time to recurrence. Stepwise multivariate logistic regression analyses were performed to assess for factors associated with high postoperative growth rate. The cutoff for high growth was set at the median rate for patients with postoperative tumor growth. JMP Pro (version 14, SAS Institute Inc.) was used for all analyses. A p value $<0.05$ was considered statistically significant.

\section{Results}

\section{Preoperative Characteristics}

The pre- and postoperative characteristics of the 141 patients who underwent subtotal resection of an intracranial WHO grade I meningioma are summarized in Table 1 . The average age $( \pm$ SD) was $56.55 \pm 12.76$ years, and 40 $(28 \%)$ were male. Ninety-four patients $(67 \%)$ were White, 29 (21\%) were African American, 2 (1\%) were Hispanic, $3(2 \%)$ were Asian, and $13(9 \%)$ were of unknown/other race. The median (interquartile range, IQR) preoperative volume was $17.19 \mathrm{~cm}^{3}$ (IQR 7.47-38.43 $\mathrm{cm}^{3}$ ). Preoperatively, the median annual relative growth rate and absolute growth rate were $7.85 \%$ (IQR $0 \%-63 \%$ ) and $0.75 \mathrm{~cm}^{3} /$ year (IQR 0-6.24 $\mathrm{cm}^{3} /$ year), respectively. The median Karnofsky Performance Scale (KPS) score was 80 (IQR 80-80). Of the 141 tumors, 49 (35\%) were located centrally (medial sphenoid wing, olfactory groove, planum sphenoidale, suprasellar), 90 (64\%) were skull base, 12 (9\%) were convexity, $41(30 \%)$ were falcine/parasagittal, 34 (24\%) were sphenoid wing, $10(7 \%)$ were olfactory groove, $21(15 \%)$ were planum sphenoidale, $14(10 \%)$ were suprasellar, 13 (9\%) were tentorial, and $29(21 \%)$ were in the posterior fossa.

\section{Postoperative Characteristics}

Following surgery, the median postoperative volume was $2.31 \mathrm{~cm}^{3}$ (IQR $0.98-5.16 \mathrm{~cm}^{3}$ ), with a percentage resection of $82 \%$ (IQR 68\%-93\%). Seventy-four patients $(52 \%)$ had tumor recurrence, in which the median time to recurrence was 14 months (IQR 6-34 months). In all patients postoperatively, the median annual relative growth rate and absolute growth rate were 5.11\% (IQR 0\%-37\%) and $0.09 \mathrm{~cm}^{3} /$ year (IQR $0-1.39 \mathrm{~cm}^{3} /$ year), respectively. In patients with tumor recurrence, the median annual relative growth rate and absolute growth rate were $36 \%$ (IQR $13 \%-111 \%$ ) and $1.28 \mathrm{~cm}^{3} /$ year (IQR $0.43-3.60 \mathrm{~cm}^{3} /$ year), respectively. The median follow-up duration for all patients was 45 months (IQR 22-72 months). For patients without recurrence, the median follow-up duration was 51 months (IQR 22-71 months).

\section{Factors Associated With Recurrence}

The recurrence-free survival for all patients is depicted 
TABLE 1. Patient characteristics for the 141 patients with residual tumor after primary resection of a WHO grade I meningioma

\begin{tabular}{|c|c|}
\hline Variable & Value \\
\hline \multicolumn{2}{|l|}{ Demographics } \\
\hline Mean age $\pm S D$, yrs & $56.55 \pm 12.76$ \\
\hline Male, $\mathrm{n}(\%)$ & $40(28)$ \\
\hline Median preop KPS score (IQR) & $80(80-80)$ \\
\hline \multicolumn{2}{|l|}{ Race, $n(\%)$} \\
\hline White & $94(67)$ \\
\hline African American & $29(21)$ \\
\hline Hispanic & $2(1)$ \\
\hline Asian & $3(2)$ \\
\hline Unknown/other & $13(9)$ \\
\hline \multicolumn{2}{|l|}{ Tumor characteristics } \\
\hline \multicolumn{2}{|l|}{ Location, n (\%) } \\
\hline $\begin{array}{l}\text { Central: medial sphenoid, olfactory groove, } \\
\text { planum, suprasellar }\end{array}$ & $49(35)$ \\
\hline $\begin{array}{l}\text { Peripheral: convexity and lateral sphenoid } \\
\text { wing }\end{array}$ & $21(15)$ \\
\hline Skull base & $90(64)$ \\
\hline Convexity & $12(9)$ \\
\hline Parasagittal & $24(17)$ \\
\hline Falcine & $17(12)$ \\
\hline Lateral sphenoid wing & $6(4)$ \\
\hline Middle sphenoid wing & $2(1)$ \\
\hline Medial sphenoid wing & $26(18)$ \\
\hline Olfactory groove & $10(7)$ \\
\hline Planum sphenoidale & $21(15)$ \\
\hline Suprasellar & $14(10)$ \\
\hline Tentorial & $13(9)$ \\
\hline Posterior fossa & $29(21)$ \\
\hline Cerebellopontine angle & $20(14)$ \\
\hline Foramen magnum & $4(3)$ \\
\hline Median preop tumor volume (IQR), $\mathrm{cm}^{3}$ & $17.19(7.47-38.43)$ \\
\hline Median postop tumor volume (IQR), $\mathrm{cm}^{3}$ & $2.31(0.98-5.16)$ \\
\hline Median percentage tumor resected (IQR), \% & $82(68-93)$ \\
\hline \multicolumn{2}{|l|}{ Median annual relative growth rate (IQR), \% } \\
\hline Preop & $7.85(0-63)$ \\
\hline Postop & $5.11(0-37)$ \\
\hline \multicolumn{2}{|l|}{ Median absolute growth rate (IQR), $\mathrm{cm}^{3} / \mathrm{yr}$} \\
\hline Preop & $0.75(0-6.24)$ \\
\hline Postop & $0.09(0-1.39)$ \\
\hline \multicolumn{2}{|l|}{ Long-term outcomes } \\
\hline Median follow-up duration (IQR), mos & $45(22-71)$ \\
\hline Recurrence, $\mathrm{n}(\%)$ & $74(52)$ \\
\hline Median time to recurrence (IQR), mos & $14(6-34)$ \\
\hline Postop chemotherapy, n (\%) & $0(0)$ \\
\hline Surgery for recurrence, $\mathrm{n}(\%)$ & $14(10)$ \\
\hline Radiation for recurrence, $\mathrm{n}(\%)$ & $25(18)$ \\
\hline
\end{tabular}

in Fig. 1. The recurrence-free survival at 1, 2, 3, and 5 years was $72 \%, 63 \%, 51 \%$, and $41 \%$, respectively. The factors associated with time to recurrence are summarized in Table 2. In stepwise multivariate analysis, recurrence was significantly associated with preoperative tumor volume (hazard ratio [HR] 1.008, 95\% confidence interval [CI] $1.002-1.013, \mathrm{p}=0.008$ ), falcine location (HR 2.215, 95\%

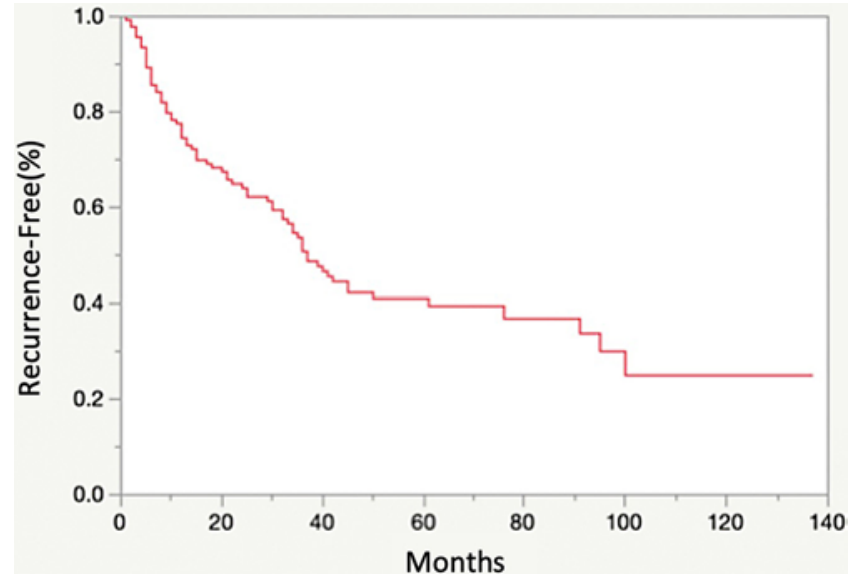

FIG. 1. Kaplan-Meier curve of recurrence-free survival for all patients who underwent initial subtotal resection of a WHO grade I intracranial meningioma. Figure is available in color online only.

TABLE 2. Stepwise multivariate proportional hazards analysis with factors associated with time to recurrence

\begin{tabular}{lcc}
\hline \multicolumn{1}{c}{ Risk Factor } & $\mathrm{p}$ Value & $\mathrm{HR}(95 \% \mathrm{Cl})$ \\
\hline Multivariate analysis & & \\
$\quad$ Preop tumor volume & 0.008 & $1.008(1.002-1.013)$ \\
Falcine location & 0.021 & $2.215(1.179-4.161)$ \\
African American & 0.044 & $1.811(1.042-3.146)$ \\
$\quad$ Tentorial location & 0.024 & $2.410(1.203-4.829)$ \\
\hline $\begin{array}{c}\text { Factors not associated w/ time to re- } \\
\text { currence in multivariate analysis }\end{array}$ & & \\
$\quad$ Postop residual tumor volume & 0.531 & $1.016(0.966-1.067)$ \\
\hline & &
\end{tabular}

CI 1.179-4.161, $\mathrm{p}=0.021)$, tentorial location (HR 2.410, 95\% CI 1.203-4.829, $\mathrm{p}=0.024)$, and African American race (HR 1.811, 95\% CI 1.042-3.146, $\mathrm{p}=0.044)$. These factors are displayed in Fig. 2. To determine the preoperative tumor volume most associated with recurrence, proportional hazards analyses were performed with preoperative volume dichotomized in 5-cm increments, and the most significant benefit occurred with preoperative tumor volume $<10 \mathrm{~cm}^{3}$ (HR 0.396, 95\% CI 0.227-0.691, $\mathrm{p}$ $=0.0004)$. Postoperative tumor residual volume $(\mathrm{RV})$ was not associated with recurrence in the stepwise multivariate analysis (HR 1.016, 95\% CI 0.966-1.067, $\mathrm{p}=0.531$ ).

\section{Associations With High Absolute Annual Growth Rate}

High absolute growth rate was defined as growth above the median growth rate among tumors with postoperative growth, which was $>1.28 \mathrm{~cm}^{3} / y e a r$. The factors associated with high absolute annual growth rate are summarized in Table 3. In stepwise multivariate logistic regression, high absolute annual growth rate was significantly associated with postoperative tumor volume (odds ratio [OR] 1.175, 95\% CI 1.078-1.280, p < 0.0001; Fig. 3). High absolute growth rate was not associated with medial sphenoid wing location (OR 1.677, 95\% CI 0.572-4.918, $\mathrm{p}=0.352)$, tentorial location (OR 2.104, 95\% CI 0.474-9.335, $\mathrm{p}=$ 

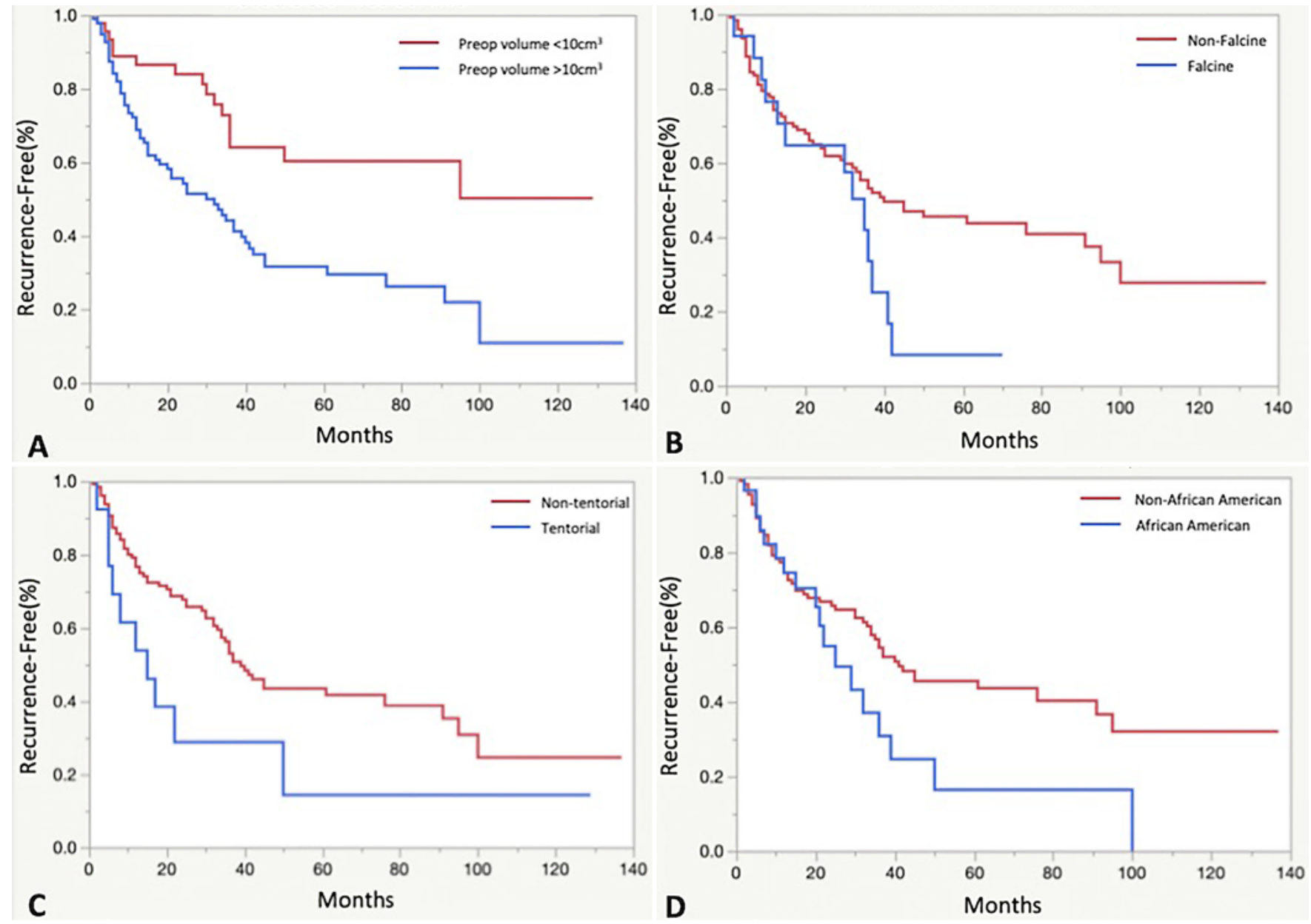

FIG. 2. Kaplan-Meier curves of recurrence-free survival in all subtotally resected meningiomas dichotomized for preoperative volume $<10 \mathrm{~cm}^{3}(\mathbf{A})$, falcine location (B), tentorial location (C), and African American race (D). Figure is available in color online only.

0.339), male patients (OR 1.670, 95\% CI 0.685-4.072, $\mathrm{p}=$ 0.262 ), falcine location (OR 2.149, 95\% CI 0.679-6.797, p $=0.201)$, preoperative tumor volume $(\mathrm{OR} 1.010,95 \% \mathrm{CI}$ $0.998-1.023, \mathrm{p}=0.111$ ), or African American race (OR $0.297,95 \%$ CI $0.086-1.1034, \mathrm{p}=0.056$ ).

\section{Residual Volume Analysis}

To determine the RV that was maximally associated with high absolute annual growth rate, logistic regressions were performed with RVs dichotomized in $1-\mathrm{cm}^{3}$ increments. The most significant benefit occurred with a postoperative tumor volume of $<5 \mathrm{~cm}^{3}$ (OR $4.526,95 \% \mathrm{CI}$ $1.992-10.29, p=0.0003)$. In stepwise multivariate analysis including the new $<5 \mathrm{~cm}^{3}$ benefit target, high absolute growth rate was significantly associated with postoperative volume $>5 \mathrm{~cm}^{3}$ (OR 4.056, 95\% CI 1.675-9.822, $\mathrm{p}$ $=0.002)$, preoperative tumor volume $(\mathrm{OR} 1.014,95 \% \mathrm{CI}$ $1.002-1.026, \mathrm{p}=0.015$ ), and African American race (OR $0.284,95 \%$ CI 0.081-0.996, $\mathrm{p}=0.032$; Table 3). High absolute growth rate was not associated with tentorial location (OR 1.966, 95\% CI 0.427-9.058, $\mathrm{p}=0.394$ ), medial sphenoid wing location (OR 1.681, 95\% CI 0.566-4.988, $\mathrm{p}=0.355)$, male patients (OR 1.741, 95\% CI 0.707-4.288, $\mathrm{p}=0.228)$, or falcine location (OR $2.374,95 \%$ CI $0.733-$ $7.683, \mathrm{p}=0.156)$.

\section{Discussion}

Maximal safe resection is the tenet of meningioma management, with the aim of removing involved dura and bone. Despite innovative surgical techniques and highresolution imaging, subtotal resections still occur $30 \%$ of the time..$^{25,32,40}$ Of the 796 patients with a WHO grade I meningioma in this present study, $22.74 \%(n=181)$ underwent radiographic subtotal resections. Simpson's paper in 1957 offers compelling evidence of the inverse association between extent of resection and tumor recurrence. ${ }^{41}$ With an increased risk for recurrence, patients with subtotal resections therefore require careful management to mitigate this risk. In the 141 subtotal resections analyzed in this study, we found that preoperative tumor volume, falcine location, tentorial location, and African American race were predictors of tumor recurrence. Additionally, we found that postoperative RV was associated with a high absolute annual growth rate, with the most resection benefit occurring at an RV $<5 \mathrm{~cm}^{3}$. These findings can help guide decisions regarding extent of resection in specific 
TABLE 3. Stepwise multivariate logistic regression of factors associated with high growth rate

\begin{tabular}{|c|c|c|}
\hline Risk Factor & $\mathrm{p}$ Value & OR $(95 \% \mathrm{Cl})$ \\
\hline \multicolumn{3}{|l|}{$\begin{array}{l}\text { Multivariate stepwise logistic regres- } \\
\text { sion }\end{array}$} \\
\hline Postop volume* & $<0.0001$ & $1.175(1.078-1.280)$ \\
\hline \multicolumn{3}{|l|}{$\begin{array}{l}\text { Factors not associated } w / \text { high } \\
\text { absolute growth rate in multivariate } \\
\text { analysis }\end{array}$} \\
\hline Medial sphenoid wing location & 0.352 & $1.677(0.572-4.918)$ \\
\hline Tentorial location & 0.339 & $2.104(0.474-9.335)$ \\
\hline Male & 0.262 & 1.670 \\
\hline Falcine locat & 0.201 & $2.149(0.679-6.797)$ \\
\hline Preop tumor & 11 & 1.010 \\
\hline African American race & 56 & 0.297( \\
\hline \multicolumn{3}{|l|}{$\begin{array}{l}\text { Multivariate stepwise logistic regres- } \\
\text { sion }\end{array}$} \\
\hline Postop volume $>5 \mathrm{~cm}^{3 *}$ & 0.002 & $4.056(1$ \\
\hline Preop tumor volume & 0.015 & $1.014(1.002-1.026)$ \\
\hline African American race & 0.032 & $0.284(0.081-0.996)$ \\
\hline \multicolumn{3}{|l|}{$\begin{array}{l}\text { Factors not associated } w / \text { high } \\
\text { absolute growth rate in multivariate } \\
\text { analysis }\end{array}$} \\
\hline Tentorial location & 0.394 & $1.966(0.427-9.058)$ \\
\hline Medial sphenoid wing location & 0.355 & $1.681(0.566-4.988)$ \\
\hline Male & 0.228 & $1.741(0.707-4.288)$ \\
\hline Falcine location & 0.156 & $2.374(0.733-7.683)$ \\
\hline
\end{tabular}

The cutoff for high growth rate was set at the median rate for patients with postoperative growth, which was $>1.28 \mathrm{~cm}^{3}$ absolute annual growth rate.

* Postoperative volume was first assessed as a continuous variable, and then as a dichotomous variable with the $<5 \mathrm{~cm}^{3}$ target.

patients and potentially limit previously described morbidities associated with meningioma progression/treatment. $5,6,10,28$

In this study, 74 patients (52\%) who had subtotal resections had tumor recurrence. This rate of recurrence is within the range of previous findings..$^{20,29,38,41}$ We identified an association between preoperative tumor volume and recurrence. It has previously been shown in WHO grade I-III meningiomas that preoperative volume is significantly associated with a higher rate of tumor recurrence. ${ }^{7,17,21}$ We previously found parafalcine location as a predictor of recurrence in subtotally resected meningiomas of all WHO grades. ${ }^{11}$ In the present study, we demonstrated that falcine location is predictive of recurrence, which is in accordance with other studies of WHO grade I meningiomas. ${ }^{2,9,23,30,35}$ This finding may be explained by limitations of resection due to the sagittal sinus, narrow operative corridor, differences in blood flow, or anatomical variations in freedom of growth compared to areas such as the skull base. We also identified tentorial location as a predictor of recurrence that, to our knowledge, has not been previously identified. Notably, Gallagher et al. did not find tumor location, including the parasagittal region, to be a significant predictor of recurrence/progression free survival in 145 patients with WHO grade I meningioma. ${ }^{14}$ Our finding of African American race as a risk factor for

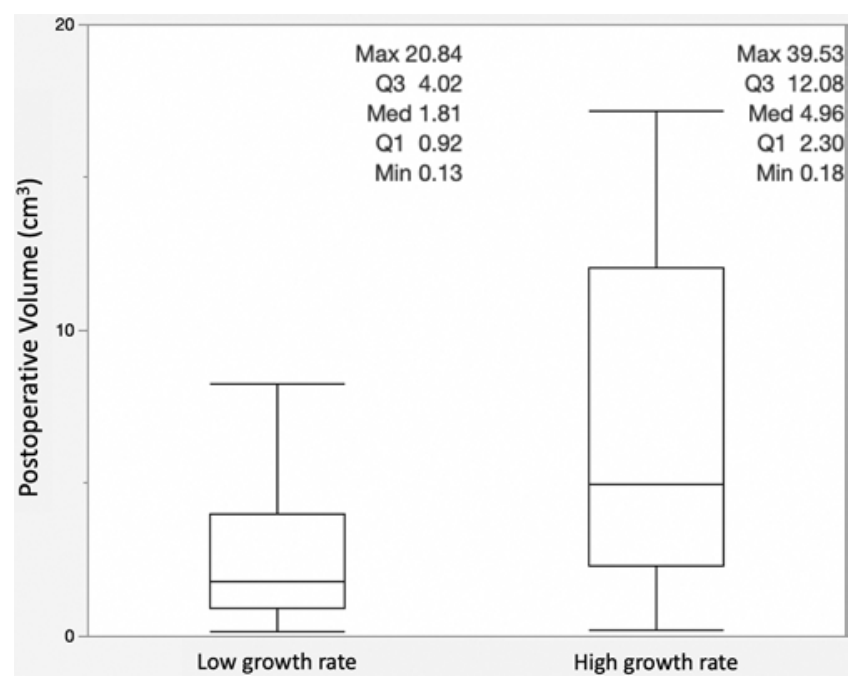

FIG. 3. Box plot comparing postoperative tumor volume between tumors with high absolute growth rate and low absolute growth rate. Q1 = quartile 1, Q3 = quartile 3 .

recurrence is in concordance with our previous findings in subtotal resections. ${ }^{9}$

Growth rates in meningiomas have been shown to vary greatly, ranging from $0.04-4.94 \mathrm{~cm}^{3} / \mathrm{year}^{7,8,12,22,33}$, ${ }^{34,37}$ However, most of the prior studies focused on incidental or nonoperated meningiomas and few studies have reported on growth rates in subtotally resected meningiomas. ${ }^{13}$ In a cohort of 33 patients who underwent subtotal resections, Nakamura et al. determined a mean absolute annual growth rate of $1.51 \mathrm{~cm}^{3} /$ year. $^{34}$ Additionally, Jung et al. studied 38 patients with subtotally resected petroclival meningiomas and found a mean growth rate of 4.94 $\mathrm{cm}^{3} /$ year. ${ }^{22}$ In our cohort of 141 patients, we defined a high growth rate as $1.28 \mathrm{~cm}^{3} /$ year. We found that RV was a predictive factor for a high absolute growth rate. This is in agreement with Nakamura et al., who also found an association between initial RV and absolute annual growth rate. ${ }^{34}$ Several studies have also found a relationship between tumor volume and growth rate in nonoperated meningiomas, ${ }^{33,38}$ while other similar studies have found no such relationship. ${ }^{18}$

When RV was stratified in $1-\mathrm{cm}^{3}$ increments, we found that $\mathrm{RV}>5 \mathrm{~cm}^{3}$ was associated with high growth rates. To our knowledge, no previous study has identified a volumetric resection target to reduce growth rates. These findings highlight the importance of maximal resection and can help guide selection of patients for adjuvant therapies. Although radiation therapy after subtotal resections has shown a survival benefit for patients with WHO grade I meningiomas, ${ }^{1,3,16,31,36,42,44}$ the optimal timing and patient selection have yet to be determined. While adjuvant as opposed to salvage radiotherapy is often reserved for younger patients with tumors in symptomatic locations, our findings indicate a potential benefit to early adjuvant intervention in patients with additional risk factors for recurrence and hastened growth. By identifying predictors of recurrence and high growth rate, our study helps identify appropriate patients for adjuvant radiation ther- 
apy and/or more frequent postoperative monitoring, and future studies can help elucidate the optimal therapy and surveillance timing patterns so as to ultimately continue individualizing follow-up management. ${ }^{27}$

\section{Strength and Limitations}

This study provides valuable information for the care of meningiomas. There have been a limited number of studies reporting on growth rates in meningiomas, especially following resection. We used volumetric measurement with image-analysis software to track disease progression. This method is regarded as the superior method for capturing the 3D nature of meningiomas.,39,45 Our study establishes predictors of recurrence and growth rate in a larger population than previous studies of patients with subtotal resections, and thus helps to identify resection goals and individualize follow-up management.

While this study has greater power and predictive value than previous studies, it is not without limitations. There were several populations of meningioma patients that were excluded in order to create a uniform patient population for analysis. Unfortunately, this limits the generalizability of our study. This study also has limitations of a retrospective review, including inherent bias in patient or treatment selection. Another limitation is the relatively short follow-up time in our study, as meningiomas can recur decades after surgery. Because we limited our cohort to grade I meningiomas, the impact of adjuvant therapies was not studied. It is also important to note that some patients included in this cohort may have tumor histology more consistent with WHO grade II under the new 2017 classification system. While our study utilized a linear growth rate, it is important to recognize the wide variety of growth models and that a tumor can display a variety of growth patterns over its lifetime, exhibiting exponential, linear, and no growth at different points in time. ${ }^{26,35}$ Additionally, our definition of recurrence limits our detection of subradiographic tumor growth, particularly in small tumors, although analyzing radiographically evident tumor growth maintains clinical relevancy. Finally, we did not analyze any molecular or genetic predictors of recurrence or growth rate, such as $\mathrm{Ki}-67$ or MIB-1, as screening for these markers was not routinely performed or documented for all patients at our institution.

\section{Conclusions}

While maximal resection is the goal of meningioma treatment, many patients receive subtotal resections. In this study of residual tumors, we found that preoperative tumor volume, falcine location, tentorial location, and African American race were associated with tumor recurrence. Additionally, postoperative RV was associated with a high growth rate, with the most benefit occurring at an $\mathrm{RV}<5 \mathrm{~cm}^{3}$. These findings help identify patients at risk for tumor recurrence, and can inform decisions on extent of resection, postoperative surveillance imaging, and/or adjuvant therapy.

\section{References}

1. Adegbite AB, Khan MI, Paine KW, Tan LK: The recurrence of intracranial meningiomas after surgical treatment. J Neurosurg 58:51-56, 1983

2. Alvernia JE, Dang ND, Sindou MP: Convexity meningiomas: study of recurrence factors with special emphasis on the cleavage plane in a series of 100 consecutive patients. J Neurosurg 115:491-498, 2011

3. Barbaro NM, Gutin PH, Wilson CB, Sheline GE, Boldrey EB, Wara WM: Radiation therapy in the treatment of partially resected meningiomas. Neurosurgery 20:525-528, 1987

4. Buerki RA, Horbinski CM, Kruser T, Horowitz PM, James CD, Lukas RV: An overview of meningiomas. Future Oncol 14:2161-2177, 2018

5. Chaichana KL, Jackson C, Patel A, Miller NR, Subramanian P, Lim M, et al: Predictors of visual outcome following surgical resection of medial sphenoid wing meningiomas. J Neurol Surg B Skull Base 73:321-326, 2012

6. Chaichana KL, Pendleton C, Zaidi H, Olivi A, Weingart JD, Gallia GL, et al: Seizure control for patients undergoing meningioma surgery. World Neurosurg 79:515-524, 2013

7. Chang V, Narang J, Schultz L, Issawi A, Jain R, Rock J, et al: Computer-aided volumetric analysis as a sensitive tool for the management of incidental meningiomas. Acta Neurochir (Wien) 154:589-597, 2012

8. Dirks MS, Butman JA, Kim HJ, Wu T, Morgan K, Tran AP, et al: Long-term natural history of neurofibromatosis Type 2-associated intracranial tumors. J Neurosurg 117:109-117, 2012

9. Ehresman JS, Garzon-Muvdi T, Rogers D, Lim M, Gallia GL, Weingart J, et al: The relevance of Simpson grade resections in modern neurosurgical treatment of World Health Organization grade I, II, and III meningiomas. World Neurosurg 109:e588-e593, 2018

10. Ehresman JS, Garzon-Muvdi T, Rogers D, Lim M, Gallia GL, Weingart J, et al: Risk of developing postoperative deficits based on tumor location after surgical resection of an intracranial meningioma. J Neurol Surg B Skull Base 80:59-66, 2019

11. Ehresman JS, Mampre D, Rogers D, Olivi A, Quinones-Hinojosa A, Chaichana KL: Volumetric tumor growth rates of meningiomas involving the intracranial venous sinuses. Acta Neurochir (Wien) 160:1531-1538, 2018

12. Evers S, Verbaan D, Sanchez E, Peerdeman S: 3D volumetric measurement of neurofibromatosis type 2-associated meningiomas: association between tumor location and growth rate. World Neurosurg 84:1062-1069, 2015

13. Fountain DM, Soon WC, Matys T, Guilfoyle MR, Kirollos R, Santarius T: Volumetric growth rates of meningioma and its correlation with histological diagnosis and clinical outcome: a systematic review. Acta Neurochir (Wien) 159:435-445, 2017

14. Gallagher MJ, Jenkinson MD, Brodbelt AR, Mills SJ, Chavredakis E: WHO grade 1 meningioma recurrence: are location and Simpson grade still relevant? Clin Neurol Neurosurg 141:117-121, 2016

15. Gittleman HR, Ostrom QT, Rouse CD, Dowling JA, de Blank PM, Kruchko CA, et al: Trends in central nervous system tumor incidence relative to other common cancers in adults, adolescents, and children in the United States, 2000 to 2010. Cancer 121:102-112, 2015

16. Glaholm J, Bloom HJ, Crow JH: The role of radiotherapy in the management of intracranial meningiomas: the Royal Marsden Hospital experience with 186 patients. Int J Radiat Oncol Biol Phys 18:755-761, 1990

17. Gousias K, Schramm J, Simon M: The Simpson grading revisited: aggressive surgery and its place in modern meningioma management. J Neurosurg 125:551-560, 2016

18. Hashimoto N, Rabo CS, Okita Y, Kinoshita M, Kagawa N, Fujimoto Y, et al: Slower growth of skull base meningiomas compared with non-skull base meningiomas based on volu- 
metric and biological studies. J Neurosurg 116:574-580, 2012

19. Hasseleid BF, Meling TR, Rønning P, Scheie D, Helseth E: Surgery for convexity meningioma: Simpson Grade I resection as the goal: clinical article. J Neurosurg 117:999-1006, 2012

20. Hortobágyi T, Bencze J, Varkoly G, Kouhsari MC, Klekner Á: Meningioma recurrence. Open Med (Wars) 11:168-173, 2016

21. Ildan F, Erman T, Göçer AI, Tuna M, Bağdatoğlu H, Cetinalp $\mathrm{E}$, et al: Predicting the probability of meningioma recurrence in the preoperative and early postoperative period: a multivariate analysis in the midterm follow-up. Skull Base 17:157-171, 2007

22. Jung HW, Yoo H, Paek SH, Choi KS: Long-term outcome and growth rate of subtotally resected petroclival meningiomas: experience with 38 cases. Neurosurgery 46:567-575, 2000

23. Ko CC, Chen TY, Lim SW, Kuo YT, Wu TC, Chen JH: Prediction of recurrence in parasagittal and parafalcine meningiomas: added value of diffusion-weighted magnetic resonance imaging. World Neurosurg 124:e470-e479, 2019

24. Lemée JM, Corniola MV, Da Broi M, Joswig H, Scheie D, Schaller K, et al: Extent of resection in meningioma: predictive factors and clinical implications. Sci Rep 9:5944, 2019

25. Levine ZT, Buchanan RI, Sekhar LN, Rosen CL, Wright DC: Proposed grading system to predict the extent of resection and outcomes for cranial base meningiomas. Neurosurgery 45:221-230, 1999

26. Louis DN, Ohgaki H, Wiestler OD, Cavenee WK, Burger PC, Jouvet A, et al: The 2007 WHO classification of tumours of the central nervous system. Acta Neuropathol 114:97-109, 2007

27. Lu VM, Goyal A, Lee A, Jentoft M, Quinones-Hinojosa A, Chaichana KL: The prognostic significance of TERT promoter mutations in meningioma: a systematic review and meta-analysis. J Neurooncol 142:1-10, 2019

28. Lu VM, Wahood W, Akinduro OO, Parney IF, QuinonesHinojosa A, Chaichana KL: Four independent predictors of postoperative seizures after meningioma surgery: a metaanalysis. World Neurosurg 130:537-545.e3, 2019

29. McGovern SL, Aldape KD, Munsell MF, Mahajan A, DeMonte F, Woo SY: A comparison of World Health Organization tumor grades at recurrence in patients with non-skull base and skull base meningiomas. J Neurosurg 112:925933, 2010

30. Melamed S, Sahar A, Beller AJ: The recurrence of intracranial meningiomas. Neurochirurgia (Stuttg) 22:47-51, 1979

31. Miralbell R, Linggood RM, de la Monte S, Convery K, Munzenrider JE, Mirimanoff RO: The role of radiotherapy in the treatment of subtotally resected benign meningiomas. J Neurooncol 13:157-164, 1992

32. Mirimanoff RO, Dosoretz DE, Linggood RM, Ojemann RG, Martuza RL: Meningioma: analysis of recurrence and progression following neurosurgical resection. J Neurosurg 62:18-24, 1985

33. Nakamura M, Roser F, Michel J, Jacobs C, Samii M: The natural history of incidental meningiomas. Neurosurgery 53:62-71, 2003

34. Nakamura M, Roser F, Michel J, Jacobs C, Samii M: Volumetric analysis of the growth rate of incompletely resected intracranial meningiomas. Zentralbl Neurochir 66:17-23, 2005
35. Nakasu S, Fukami T, Nakajima M, Watanabe K, Ichikawa M, Matsuda M: Growth pattern changes of meningiomas: longterm analysis. Neurosurgery 56:946-955, 2005

36. Ohba S, Kobayashi M, Horiguchi T, Onozuka S, Yoshida K, Ohira T, et al: Long-term surgical outcome and biological prognostic factors in patients with skull base meningiomas. J Neurosurg 114:1278-1287, 2011

37. Olivero WC, Lister JR, Elwood PW: The natural history and growth rate of asymptomatic meningiomas: a review of 60 patients. J Neurosurg 83:222-224, 1995

38. Oya S, Kawai K, Nakatomi H, Saito N: Significance of Simpson grading system in modern meningioma surgery: integration of the grade with MIB-1 labeling index as a key to predict the recurrence of WHO Grade I meningiomas. J Neurosurg 117:121-128, 2012

39. Oya S, Kim SH, Sade B, Lee JH: The natural history of intracranial meningiomas. J Neurosurg 114:1250-1256, 2011

40. Pollock BE, Stafford SL, Link MJ: Gamma knife radiosurgery for skull base meningiomas. Neurosurg Clin N Am 11:659-666, 2000

41. Simpson D: The recurrence of intracranial meningiomas after surgical treatment. J Neurol Neurosurg Psychiatry 20:22-39, 1957

42. Soyuer S, Chang EL, Selek U, Shi W, Maor MH, DeMonte F: Radiotherapy after surgery for benign cerebral meningioma. Radiother Oncol 71:85-90, 2004

43. Sughrue ME, Kane AJ, Shangari G, Rutkowski MJ, McDermott MW, Berger MS, et al: The relevance of Simpson Grade I and II resection in modern neurosurgical treatment of World Health Organization Grade I meningiomas. J Neurosurg 113:1029-1035, 2010

44. Taylor BW Jr, Marcus RB Jr, Friedman WA, Ballinger WE Jr, Million RR: The meningioma controversy: postoperative radiation therapy. Int J Radiat Oncol Biol Phys 15:299-304, 1988

45. Vakilian S, Souhami L, Melançon D, Zeitouni A: Volumetric measurement of vestibular schwannoma tumour growth following partial resection: predictors for recurrence. J Neurol Surg B Skull Base 73:117-120, 2012

\section{Disclosures}

The authors report no conflict of interest concerning the materials or methods used in this study or the findings specified in this paper.

\section{Author Contributions}

Conception and design: Chaichana. Acquisition of data: all authors. Analysis and interpretation of data: all authors. Drafting the article: all authors. Critically revising the article: all authors. Reviewed submitted version of manuscript: all authors. Approved the final version of the manuscript on behalf of all authors: Chaichana. Statistical analysis: Chaichana, Materi, Mampre. Administrative/technical/material support: Chaichana. Study supervision: Chaichana.

\section{Correspondence}

Kaisorn L. Chaichana: Mayo Clinic Florida, Jacksonville, FL. chaichana.kaisorn@mayo.edu. 